\section{PENELITIAN PENGARUH TEKNIK PENCETAKAN \\ KOMPON SOL KARET TERHADAP SIFAT FISISNYA}

Oleh : Dwi Wahini Nurhajati, Agustin Suraswati, Pramono dan Supriyadi

\section{ABSTRACT}

The objective of this research is to know the influence of molding techique to the physical properties for rubber sole compound by a hydraulic press nachine and a vulcanization molding machine. In the same process condition, here are the physical properties different between the soles were molded by a ydraulic press machine and the soles were molded by a vulcanization molding hachine. Optimal physical test value for the soles were molded by a hydraulic ress machine was reached on the vulcanization time $15 \mathrm{~min}$ at temperature $65^{\circ} \mathrm{C}$, and pressure $100 \mathrm{~kg} / \mathrm{cm}^{2}$, whereas optimal physical test value for the oles were molded by a vulcanization molding machine was reached on the vulanization time $20 \mathrm{~min}$, at temperature $165^{\circ} \mathrm{C}$, and pressure $1500 \mathrm{psi}$.

\section{INTISARI}

Penelitian ini bertujuan untuk mengetahui pengaruh teknik pencetakan compon sol karet dengan mesin "hydraulic press" dan mesin cetak vulkanisasi erhadap sifat fisisnya. Pada kondisi proses yang sama ada perbedaan sifat fisis intara sol yang dicetak dengan mesin "hydraulic press" dan mesin cetak vulranisasi. Sifat fisis optimal untuk sol karet yang dicetak dengan mesin "hydraulic ress" dicapai dalam waktu 15 menit pada suhu $165^{\circ} \mathrm{C}$ dan tekanan $100 \mathrm{~kg} / \mathrm{cm}^{2}$. Sedangkan sifat fisis optimai untuk sol karet yang dicetak dengan mesin cetak ulkanisasi dicapai dalam waktu 20 menit pada suhu $165^{\circ} \mathrm{C}$ dan tekanan 1500 si.

\section{PENDAHULUAN}

Sifat fisis sol karet dipengaruhi oleh formula kompon, proses pembuatan compon, proses pencetakan kompon dan vulkanisasi.

Formula kompon karet untuk sol sepatu umumnya terdiri dari karet alam ebagai bahan baku dan bahan-bahan tambahan ("additive") untuk memperbaiki sifat dan mutu sol yang dihasilkan. Menurut Harry Baron (1948), bahan tambahan yang diperlukan dapat berupa bahan pengisi (filler), bahan pelunak (softener), bahan pengaktif (activator), bahan anti oksidan, bahan pencepat vulkanisasi (accelerator) dan bahan pemvulkanisasi ("vulcanizing agent').

Proses pembuatan kompon merupakan proses pencampuran bahan-bahan kimia kedalam karet secara merata. Langkah-langkah yang dikerjakan pada proses pembuatan kompon karet adalah mastikasi karet, pemasukan bahan penggiat dan anti degradasi, pemasukan sebagian bahan pengisi, pemasukan bahan pelunak dan sisa bahan pengisi, pemasukan bahan pencepat dan terakhir adalah pemasukan bahan vulkanisasi.

Ada banyak mesin atau alat yang dapat digunakan untuk mencetak kompon karet menjadi sol antara lain mesin cetak vulkanisasi, mesin calendering untuk yang berbentuk lembaran, mesin cetak injeksi, dan mesin cetak sistim hand press dengan pemanas kompor $(2,3)$.

Untuk mengetahui pengaruh teknik pencetakan kompon sol karet terhadap sifat fisisnya maka dilakukan suatu penelitian mengenai pengaruh pencetakan kompon sol karet dengan mesin "hydraulic press" untuk sol yang berbentuk lembaran dan pencetakan kompon sol karet dengan mesin cetak vulkanisasi untuk sol yang dinamakan unit sol.

\section{MATERI DAN METODE PENELITIAN}

1. Materi

1.1. Bahan

Bahan-bahan yang digunakan dalam penelitian ini meliputi :

- Bahan baku karet $=$ RSS

- Bahan penggiat ("activator") $=\mathrm{Zn} \mathrm{O}$, asam stearat

- Bahan pencepat ("accelerator") = MBT, MBTS, TMT

- Anti degradasi = PBN, Wax

- Bahan pengisi ("filler") = Carbon black

- Processing oil $=$ Napthanic oil

- Bahan pemvulkanisasi $=$ belerang

1.2. Peralatan

Alat-alat yang digunakan dalam penelitian ini antara lain : mesin two rolls mill, mesin vulkanisasi, mesin hydraulic press, timbangan, stop watch dan alat uji sifat fisis seperti : "abrasion tester", "tensile strength tester", dan "shore A durometer".

Vol. X No. 20 Tahun 1994/1995 


\section{Metode Penelitian}

\subsection{Proses Pembuatan Kompon}

Proses pembuatan kompon merupakan tahapan utama dalam pembuatan kompon dengan tujuan untuk memasukkan bahan-bahan kimia kedalam karet secara merata.

Kompon sol sepatu yang digunakan dalam penelitian ini dibuat dengan formula :

RSS $=100$ bagian $;$ Napthanic oil $=10$ bagian;

$\mathrm{Zn}=3$ bagian; Carbon black $=50$ bagian;

Asam Stearat $=2$ bagian; PBN $=3$ bagian;

$\mathrm{MBT}=0,5$ bagian; MBTS $\quad=0,5$ bagian;

TMT $=1$ bagian; Wax $=2$ bagian dan belerang $=2$ bagian .

Pada proses pembuatan kompon ini, bahan-bahan kimia didispersikan kedalam karet dengan bantuan mesin two rolls mill. Mulamula karet dimastikasi dulu sampai plastis untuk memudahkan pendispersian bahan-bahan kimia kedalam karet. Setelah plastis ditambahkan bahan-bahan tambahan seperti bahan penggiat, anti degradasi, bahan pengisi, bahan pelunak, bahan pencepat dan terakhir tambahkan belerang lalu digiling sampai homogen.

Kompon yang telah jadi dikondisikan selama 24 jam baru kemudian dicetak menjadi sol.

2.2. Proses Pencetakan Kompon Sol Karet.

\subsubsection{Pencetakan sol dengan mesin vulkanisasi}

Sol yang dicetak dengan mesin vulkanisasi mempunyai tebal bagian depan $=10 \mathrm{~mm}$ dan tebal bagian belakang $=20 \mathrm{~mm}$, dengan model sebagai berikut :

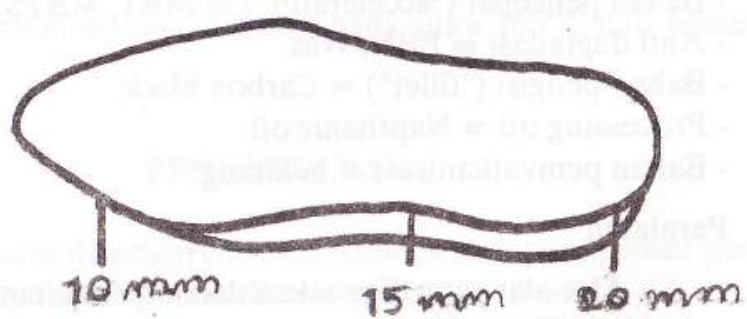

Kondisi proses penncetakan dengan mesin vulkanissi ini yaitu suhu $=165^{\circ} \mathrm{C}$, tekanan $=1500$ psi dengan variasi waktu $=7-25$ menit.
2.2.2. Pencetakan sol dengan mesin hydraulic press.

Sol yang dicetak dengan mesin hydraulic press berbentuk lembaran (slab) dengan ketebalan $10 \mathrm{~mm}$. Kondisi proses pencetakannya adalah : suhu $=165^{\circ} \mathrm{C}$, waktu bervariasi $=7-25$ menit, tekanan $=100 \mathrm{~kg} / \mathrm{cm}^{2}$.

2.3. Pengujian Sifat Fisis

Sifat fisis sol karet yang diuji pada penelitian ini meliputi :

(1). Tegangan putus dan perpanjangan putus.

Pengujian dilakukan dengan alat uji tensile strength. Potong cuplikan dengan bentuk dayung dan ukuran sebagai berikut :

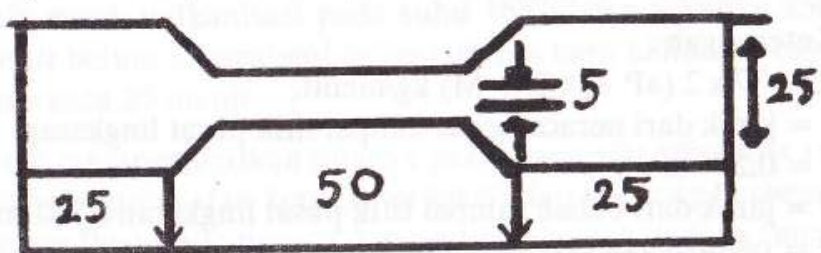

Buat tanda dua garis sejajar pada cuplikan berjarak $25,4 \mathrm{~mm}$ dari tengah-tengah dayung (dumbell). Jepit cuplikan pada alat dan lakukan penarikan dengan kecepatan $25 \pm 1 \mathrm{~cm} /$ menit sampai cuplikan putus. Catat beban maksimum yang diperlukan untuk penarikan cuplikan sampai putus dan catat pula perpanjangan putusnya.

Perhitungan :

- Tegangan putus $=\frac{\mathrm{F}}{\mathrm{t} \times \mathrm{w}} \mathrm{kg} / \mathrm{cm} 2$.

- Perpanjangan putus $=\frac{L_{1}-L_{0}}{L_{0}} \times 100 \%$.

Dimana :

$\mathrm{F}=$ beban yang diperlukan untuk menarik cuplikan sampai putus, kg.

$\mathrm{t}=$ Tebal cuplikan, $\mathrm{cm}$.

$\mathrm{w}=$ lebar cuplikan, $\mathrm{cm}$.

$L_{0}=$ panjang mula-mula antara dua garis .

$\mathrm{L}_{1}=$ panjang cuplikan antara dua garis pada waktu putus.

(2). Ketahanan kikis Grisselli.

Untuk dapat menghitung ketahanan kikis Grisselli sebelum peng ujian dimulai, harus ditentukan dulu berat jenis contoh uji. Kemudian dibuat cuplikan dengan ukuran panjang $=2 \mathrm{~cm}$, tebal $=1$ $\mathrm{cm}$. Pasang cuplikan pada tempatnya, untuk satu kàli pengujian dipasang dua buah cuplikan. Jalankan mesin selama 2 menit untuk 
meratakan cuplikan. Keluarkan cuplikan, kemudian timbang dengan teliti, lalu pasang lagi pada tempat semuia.

Jalankan mesin selama 6 menit untuk mengikis cuplikan. Waktu mesin berjalan, atur neraca pegas sedemikian rupa sehingga lengan neraca letaknya tetap seimbang yaitu terletak antara 2 pena. Pompa angin dipasang untuk membersihkan kotoran atau debu yang menempel akibat terjadinya penggosokan tersebut. Catat pembacaan timbangan neraca pegas tiap-tiap menit. Setelah 6 menit keluarkan kedua cuplikan lalu ditimbang.

Perhitungan :

Ketahanan kikis $=\frac{\mathrm{W}_{0}-\mathrm{w}_{1}}{\mathrm{X} \times \mathrm{BJ} \times \mathrm{E}} \times \mathrm{mm}^{3} / \mathrm{kgm}$.

Keterangan :

$E=37 \times 2(a P+b Q+M) \mathrm{kg} / \mathrm{menit}$.

$a=$ jarak dari neraca pegas sampai titik pusat lingkaran

$=0,255 \mathrm{~m}$.

$\mathrm{b}=$ jarak dari beban sampai titik pusat lingkaran $0,381 \mathrm{~m}$

$\mathrm{P}=$ pembacaan rata-rata dari neraca pegas, $\mathrm{kcs}$.

$\mathrm{Q}=$ berat beban rata-rata, $\mathrm{kg}$.

$\mathbf{M}=$ momen mesin, nol.

$\mathrm{w}_{\mathrm{o}}=$ berat mula-mula setelah diratakan selama 2 menit, gr

$\mathbf{w}_{1}=$ berat setelah pengikisan, gram

$\mathrm{t}=$ waktu pengikisan, 6 menit

$\mathrm{BJ}=$ bobot jenis, $\mathrm{gr} / \mathrm{cm}^{3}$

(3). Kekerasan

Pengujian dilakukan dengan alat uji "Hardness tester shore A Durometer". Potong cuplikan dengan tebal sekurang-kurangnya $6,3 \mathrm{~mm}$ dan lebar sekurang-kurangnya $2,54 \mathrm{~cm}$. Cuplikan diletakkan di atas dasar yang keras dan datar. Letakkan alat tegak lurus. Letakkan telunjuk pada bagian alas alat. Tekan alat pada permukaan contoh sampai kaki penekan alat menyentuh dan sejajar dengan permukaan contoh. Pembacaan skala dilakukan segera setelah diperoleh kontak yang erat dan sejajar tadi, lakukan 3 kali pengujian dan diambil rata-ratanya.

\section{HASIL DAN PEMBAHASAN}

Hasil penelitian mengenai pengaruh proses pencetakan kompon sol karet gan mesin cetak vulkanisasi dan mesin "hydraulic press" terhadap kematangsol dan sifat fisisnya dapat dilihat pada tabel 1 dan 2.
Dari tabel I terlihat hahwa sol yang dicetak dengan mesin hydraulic press sudah masak dalam waktu 12,5 menit, sedangkan sol yang dicetak dengan mesin cetak vulkanisasi ("unit sol") baru masak dalam waktu 15 menit. Perbedaan ini kemungkinan disebahkan karena tebal yang berbeda dan juga arah pemanasan yang berbeda. Pencetakan sol menggunakan mesin hydraulic press berarti menggunakan pemanasan dua arah yaitu dari atas dan bawah, sedangkan pencetakan sol dengan mesin cetak vulkanisasi berarti menggunakan pemanasan satu arah yaitu dari arah bawah dan samping. Sol yang dicetak dengan mesin "hydraulic Press" pada suhu $165^{\circ} \mathrm{C}$ dan tekanan $100 \mathrm{~kg} / \mathrm{cm}^{2}$ dalam waktu 20 menit permukaannya terlihat rapuh, ini kemungkinan sudah terjadi degradasi pada molekulmolekul karet karena pemanasan yang terlalu lama. Sedangkan sol yang dicetak dengan mesin cetak vulkanisasi pada suhu $165^{\circ} \mathrm{C}$ dan tekanan 1500 psi dalam waktu 20 menit belum mengalami degradasi dan baru kelihatan rapuh permukaannya dalam waktu 25 menit.

Tabel 2 memperlihatkan adanya perbedaan siat-sifat fisis (iegangan putus, perpanjangan putus dan ketahanan kikis) dari sol yang berbentuk lcmbaran (dicetak dengan "hydraulic press") dan unit sol dicetak dengan "mesin cetak vul. kanisasi" pada kondisi proses yang sama. Hal ini mungkin dikarenakan kemasakan sol yang berbeda yang discbabkan tebal sol dan arah pemanasan yang berbeda. Sifat fisis terbaik untuk sol yang dicetak dengan mesin hydraulic press diperoleh pada kondisi proses dengan suhu $165^{\circ} \mathrm{C}$ dan tekanan $100 \mathrm{~kg} / \mathrm{cm}^{2}$ dalam waktu 15 menit. Sedangkan untuk sol yang dicetak dengan mesin cetak vulkanisasi maka sifat fisis terbaik diperoleh pada kondisi proses dengan suhu $165^{\circ} \mathrm{C}$ dan tekanan 1500 psi dalam wakı 20 menit.

\section{KESIMPULAN}

1. Ada perbedaan sifat fisis antara sol yang dicetak dengan mesin "hydraulic press" dan mesin cetak vulkanisasi pada kondisi proses yang sama

2. Sifat fisis terbaik untuk sol karet yang dicetak dengan mesin "hydraulic press" diperoleh dalam waktu 15 menit pada suhu $165^{\circ} \mathrm{C}$, tekanan $100 \mathrm{~kg} / \mathrm{cm}^{2}$.

3. Sifat fisis terbaik untuk sol karet yang dicetak dengan mesin cetak vulkanisasi diperoleh dalam waktu 20 menit pada suhu $165^{\circ} \mathrm{C}$, tekanan $1500 \mathrm{psi}$. 
1 : Pengaruh waktu proses terhadap kematangan sol karet yang berbentuk lembaran dan unit sol (suhu proses $165^{\circ} \mathrm{C}$ ).

\begin{tabular}{|c|c|c|}
\hline \multirow{2}{*}{$\begin{array}{l}\text { Waktu pro- } \\
\text { ses (menit) }\end{array}$} & \multicolumn{2}{|c|}{ Hasil } \\
\hline & sol lembaran & unit sol \\
\hline 7 & $\begin{array}{l}\text { Permukaan sol bagian } \\
\text { luar belum begitu matang }\end{array}$ & $\begin{array}{l}\text { Permukaan sol karet bagian } \\
\text { luar belum matang, nampak } \\
\text { putih dan tidak mengkilap. }\end{array}$ \\
\hline 10 & $\begin{array}{l}\text { Permukaan sol bagian } \\
\text { luar sudah matang se- } \\
\text { dangkan bagian dalam } \\
\text { belum begitu matang. }\end{array}$ & $\begin{array}{l}\text { Permukaan sol karet bagian } \\
\text { luar kurang matang sedangkan } \\
\text { bagian dalam belum matang. }\end{array}$ \\
\hline 12,5 & $\begin{array}{l}\text { Sol bagian luar dan da- } \\
\text { lam sudah matang. }\end{array}$ & $\begin{array}{l}\text { Sol bagian luar sudah ma- } \\
\text { tang sedang bagian dalam be } \\
\text { lum begitu matang. }\end{array}$ \\
\hline 15 & $\begin{array}{l}\text { Sol bagian luar dan dalam } \\
\text { sudah matang. }\end{array}$ & $\begin{array}{l}\text { Sol bagian luar dan dalam su- } \\
\text { dah matang. }\end{array}$ \\
\hline 17,5 & $\begin{array}{l}\text { Sol bagian luar dan dalam } \\
\text { sudah matang. }\end{array}$ & $\begin{array}{l}\text { Sol bagian luar dan dalam su- } \\
\text { dah matang. }\end{array}$ \\
\hline 20 & $\begin{array}{l}\text { Sol bagian luar kelihatan } \\
\text { mulai rapuh sedang bagi- } \\
\text { an dalam belum. }\end{array}$ & $\begin{array}{l}\text { Bagian luar sudah masak, ba- } \\
\text { gian dalam sudah matang. }\end{array}$ \\
\hline 22,5 & $\begin{array}{l}\text { Permukaan bagian luar } \\
\text { rapuh dan bagian dalam } \\
\text { belum rapuh. }\end{array}$ & $\begin{array}{l}\text { Bagian luar sudah masak, } \\
\text { bagian dalam sudah matang. }\end{array}$ \\
\hline 25 & $\begin{array}{l}\text { Bagian luar rapuh sedang } \\
\text { bagian dalam belum. }\end{array}$ & $\begin{array}{l}\text { Bagian luar rapuh, bagian } \\
\text { dalam belum rapuh. }\end{array}$ \\
\hline
\end{tabular}

Tabel 2: Perbandingan sifat fisis kompon sol karet yang berupa slab dan sol jadi (suhu proses : $165^{\circ} \mathrm{C}$ ).

\begin{tabular}{|c|c|c|c|c|c|}
\hline \multicolumn{2}{|c|}{ Waktu proses (menit) } & \multirow{3}{*}{$\begin{array}{c}\begin{array}{c}\text { Ketahanan } \\
\text { kikis } \\
\mathrm{mm}^{3} / \mathrm{kgm}\end{array} \\
0,00164 \\
0,00253\end{array}$} & \multirow{3}{*}{$\begin{array}{c}\begin{array}{c}\text { Tegangan } \\
\text { putus } \\
\mathrm{kg} / \mathrm{cm}^{2}\end{array} \\
166,38 \\
105,003\end{array}$} & \multirow{3}{*}{\begin{tabular}{|c|}
$\begin{array}{c}\text { Perpanjang- } \\
\text { an putus \% }\end{array}$ \\
400 \\
200
\end{tabular}} & \multirow{3}{*}{$\begin{array}{c}\begin{array}{c}\text { Kekerasan } \\
\text { shore A }\end{array} \\
60 \\
56,3\end{array}$} \\
\hline 12,5 & Slab & & & & \\
\hline & Sol & & & & \\
\hline \multirow[t]{2}{*}{15} & Slab & 0,00157 & 186,11 & 450 & 60 \\
\hline & Sol & 0,00252 & 129,57 & 340 & 58,5 \\
\hline \multirow[t]{2}{*}{17,5} & Slab & 0,00159 & 185,19 & 430 & 75 \\
\hline & Sol & 0,00250 & 138,98 & 330 & 56,7 \\
\hline \multirow[t]{2}{*}{20} & Slab & 0,00162 & 163,43 & 425 & 65 \\
\hline & Sol & 0,00177 & 153,24 & 430 & 58,5 \\
\hline \multirow[t]{2}{*}{22,5} & Slab & 0,00183 & 155,24 & 420 & 57,5 \\
\hline & Sol & 0,00257 & 134,64 & 425 & 55 \\
\hline \multirow[t]{2}{*}{25} & Slab & 0,00185 & 153,22 & 400 & 57,5 \\
\hline & Sol & 0,00304 & 106,049 & 360 & 53,3 \\
\hline
\end{tabular}

\section{DAFTAR PUSTAKA}

1. Harry Baron, "Modern Rubber Chemistry", New York - USA, 1948.

2. SBP Board of Consultant \& Engineers, "Rubber Technology and Manufacture", SBP Chemical Engineering Series no. 69, Roop Nagar Delhi.

3. Team 2.9/Proy. PPIKKP/89-90, Penelitian Uji Coba Penerapan Sol Karet Cetak Sepatu Umum Pada Industri Kecil, Departemen Perindustrian, Yogyakarta, 1990. 